\title{
Targeted inhibition of COX-2 expression by RNA interference suppresses tumor growth and potentiates chemosensitivity to cisplatin in human gastric cancer cells
}

\author{
MICHAEL W.Y. CHAN ${ }^{1,3}$, CHRISTINE Y.P. WONG ${ }^{1}$, ALFRED S.L. CHENG ${ }^{1}$, VICTOR Y.W. CHAN ${ }^{1}$, \\ KA K. CHAN ${ }^{1}$, KA F. TO ${ }^{2}$, FRANCIS K.L. CHAN ${ }^{1}$, JOSEPH J.Y. SUNG ${ }^{1}$ and WAI K. LEUNG ${ }^{1}$ \\ Departments of ${ }^{1}$ Medicine and Therapeutics, and ${ }^{2}$ Anatomical and Cellular Pathology, \\ The Chinese University of Hong Kong, Shatin, NT, Hong Kong, P.R. China
}

Received April 20, 2007; Accepted July 6, 2007

\begin{abstract}
Abstsract. Although selective cyclooxygenase-2 (COX-2) inhibitors suppress cell proliferation in gastric cancer, it remains debatable whether their effect is mediated through COX-2 dependent or independent pathways. We investigated the effects of the targeted inhibition of COX-2 expression by small interfering RNA (siRNA) in human gastric cancer cells and compared it to the effects of treatment with a specific COX-2 inhibitor. COX-2 mRNA and proteins were significantly reduced by up to $80 \%$ on day 2 after COX-2 siRNA transfection to the gastric cancer cell line MKN45. Concentrations of prostaglandins $\mathrm{E} 2\left(\mathrm{PGE}_{2}\right)$ in the condition medium were also reduced to $30 \%$ after siRNA transfection. Transfection of COX-2 siRNA exhibited a more potent antiproliferative effect on MKN45 cells than treatment with highdose $(100 \mu \mathrm{M})$ NS398. COX-2 siRNA also significantly reduced tumor growth in nude mice. While COX-2 siRNA transfection alone had no obvious pro-apoptotic effects, unlike low-dose $(10 \mu \mathrm{M}) \mathrm{NS} 398$ it enhanced the apoptotic reaction of MKN45 cells to cisplatin therapy. In conclusion, our results demonstrate for the first time that COX-2 siRNA inhibits cell growth and enhances the chemosensitivity of gastric cancer cells. RNA interference may be a promising alternative to specific COX-2 inhibitors in the prevention and treatment of gastric cancer.
\end{abstract}

\section{Introduction}

Cyclooxygenase (COX) is responsible for the conversion of arachidonic acid to prostaglandins (PGs). There are two forms

Correspondence to: Dr Wai K. Leung, Department of Medicine and Therapeutics, 9/F Clinical Science Building, Prince of Wales Hospital, Shatin, NT, Hong Kong, P.R. China

E-mail: wkleung@cuhk.edu.hk

Present address: ${ }^{3}$ Department of Life Science and Institute of Molecular Biology, National Chung Cheng University, Chia-Yi, Taiwan, R.O.C.

Key words: gastric cancer, RNAi, COX-2 of COX enzyme. COX-1 is constitutively expressed in all tissues while $\mathrm{COX}-2$ is induced by growth factors, oncogenes and tumor promoters (1). COX-2 is up-regulated in many malignant tumors, including gastric and breast cancers $(2,3)$. Animal studies have found that tumor growth requires COX-2 expression (4) and that enhanced COX-2 expression is sufficient to induce mammary gland tumorigenesis (5). It has also been reported that the overexpression of COX-2 in rat epithelial cells leads to the inhibition of apoptosis (6). These data suggest that COX-2 plays an important role in tumorigenesis.

Gastric cancer is the leading cause of cancer death in China and the second most common cause of cancer death worldwide (7). We and others have previously shown that COX-2 is overexpressed in human gastric cancers and is associated with poor overall survival $(2,8,9)$. In an animal model the use of celecoxib, a specific COX-2 inhibitor, was shown to reduce the incidence and tumor load of chemically-induced gastric cancer in rats (10). These findings suggest that COX-2 is a potential target in gastric cancer prevention and therapy.

Although non-steroidal anti-inflammatory drugs (NSAIDs) and COX-2 inhibitors have been shown to prevent and suppress cancer growth $(11,12)$, several studies indicate that a COX-2 independent mechanism may be involved in the antitumor effect of COX-2 inhibitors. For example, NS398 is found to inhibit the oral carcinoma cell line independent of prostaglandin E2 ( $\left.\mathrm{PGE}_{2}\right)$ synthesis (13) and inhibit cell growth in a COX-2-negative pancreatic tumor cell line (14). Recent data also find that COX-2 inhibitors induce apoptosis through a novel mitochondria signaling pathway (15).

In order to investigate the role of COX-2 in gastric carcinogenesis, we used small interfering RNA (siRNA) to specifically inhibit COX-2 expression in a gastric cancer cell line. siRNA are short double-stranded RNA molecules that can target complementary mRNA for degradation through a cellular process called RNA interference (RNAi) (16). Recent studies have found that siRNA are a powerful tool for the targeted inhibition of gene expression and viral propagation $(17,18)$. In this study, we blocked COX-2 expression using siRNA in the MKN45 gastric cancer cell line. The effect of siRNA on cell growth and apoptosis induction was compared with that of the COX-2 inhibitor NS398. We also investigated 
the potential induction of chemosensitivity in gastric cancer cells by a chemotherapeutic agent under treatment with siRNA or with the COX-2 inhibitor.

\section{Materials and methods}

Cell culture and drugs. Human gastric cancer cell line MKN45 (RCB1001) was obtained from the Riken Cell Bank (Tsukuba, Japan). This cell line has been shown to have strong COX-2 expression (19). Cells were cultured in RPMI-1640 medium supplemented with $10 \%$ fetal calf serum (Invitrogen, Carlsbad, CA), $50 \mathrm{U} / \mathrm{ml}$ of penicillin and $50 \mu \mathrm{g} / \mathrm{ml}$ of streptomycin (Invitrogen). Cultures were maintained in a humidified incubator at $37^{\circ} \mathrm{C}$ with $5 \% \mathrm{CO}_{2}$.

NS398 (Cayman, Ann Arbor, MI) was used as the selective inhibitor of COX-2. The $\mathrm{IC}_{50}$ values for human recombinant COX-1 and COX-2 are 75 and $1.77 \mu \mathrm{M}$, respectively (20). Stock solution was made in $100 \%$ DMSA (Sigma, St. Louis, MO) and stored at $-20^{\circ} \mathrm{C}$. The drug was diluted with culture media on the day of the experiment. The concentration of DMSA for all treatments was $<0.157 \%$.

Construction of siRNA. siRNA for COX-2 was generated using the Silencer siRNA Construction Kit (Ambion, Austin, TX) according to the manufacturer's instruction. Oligonucleotides used for generating siRNA against COX-2 (siCOX-2) were sense 5'-AATGTCCGGGTACAATCGCACCCTGTCTC and antisense strand, 5'-AAGTGCGATTGTACCCGGACACCT GTCTC (nucleotide position, 255-275, NM_000963). The underlined nucleotide sequence was annealed to the T7 promoter sequence. The siRNA was controlled for sequence specificity by a BLAST search and did not show sequence homology to other known human genes.

Construction of siRNA expressing plasmid. To construct siCOX-2 expressing plasmid, oligonucleotides containing sequences specific for COX-2 (5'-GATCCGTGCGATTGT ACCCGGACATTCAAGAGATGTCCGGGTACAATCGC ACTTTTTTGGAAA-3' and 5'-GCACGCTAACATGGG CCTGTAAGTTCTCTACAGGCCCATGTTAGCGTGAAA AAACCTTTTCGA-3') were synthesized and annealed. COX-2 siRNA expression vector (pCOX-2), which expresses hairpin siRNA under the control of human H1 RNA polymerase III promoter, was constructed by inserting pairs of the annealed DNA oligonucleotides into the pSilencer-3.1H1 neo siRNA expressing vector that was digested with BamH1 and HindIII (Ambion). A pSilencer-3.1-H1 neo (pNEG) that expressed a hairpin siRNA with limited homology to any known sequences in the human, mouse, and rat genomes was used as a negative control (Ambion).

COX-2 siRNA transfection. MKN45 cells were plated at a density of 50000 cells/well in 6-well plates and grown to $50 \%$ confluence. After $24 \mathrm{~h}$, the cells were transfected with siRNA in oligofectamine reagent (Invitrogen) according to the manufacturer's instructions. Briefly, for each well, $4 \mu 1$ of oligofectamine reagent was incubated with $11 \mu 1$ of OptiMEM I Reduced Serum Medium (Invitrogen) for $15 \mathrm{~min}$. Subsequently, $10 \mu \mathrm{l}$ of a mixture of $40 \mu \mathrm{M}$ siRNA and $175 \mu 1$ of Opti-MEM I Reduced Serum Medium was added. After incubation for 15-20 min at room temperature, $200 \mu 1$ siRNA mixture was added to the well containing $800 \mu 1$ of serum-free RPMI-1640 and incubated for a period of 4-5 h. As a control experiment, cells were similarly transfected with either siRNA against luciferase (siGL2) (21) or oligofectamine (vehicle only). After transfection, cells were replenished with regular medium and left untreated for different periods of time. Cells, total-RNA or protein were then harvested for further analysis.

Quantitative analysis of COX-2 mRNA expression. COX-2 mRNA levels were determined by real-time quantitative RTPCR. Total-RNA was extracted by TRIzol reagent (Invitrogen) and reverse-transcripted into cDNA by MMLV (Promega, Madison, WI). The level of $C O X-2$ mRNA was examined by real-time quantitative PCR using ABI PRISM 7000 sequence detection system (Applied Biosystems, Foster City, CA). Each reaction contained $12.5 \mu \mathrm{l}$ of $2 \mathrm{x}$ SYBR supermix (Bio-Rad Laboratories, Hercules, CA), $0.2 \mu 1$ of $10 \mathrm{pm} / \mu 1$ of forward and reverse primers and $5 \mu \mathrm{l}$ of DNA template for a total volume of $25 \mu 1$. The primer sequences for $C O X-2$ are 5'-TTCAAATG AGATTGTGGGAAAATTGCT-3' (forward) and 5'-AGATC ATCTCTGCCTGAGTATCTT-3' (reverse) (22). Expression of $C O X-2$ was normalized to cDNA loading for each individual sample using $\beta$-actin (primer sequence: forward, 5'-GCATTT GCGGTGGACGATGGAGG; reverse, 5'-GGTCACCCA CACTGTGCCCATCTA) as an internal standard. Hot start PCR was initiated at $94^{\circ} \mathrm{C}$ for $6 \mathrm{~min}$ and followed by 35 cycles of denaturation at $94^{\circ} \mathrm{C}$ for $30 \mathrm{sec}$, annealing at $60^{\circ} \mathrm{C}$ for $25 \mathrm{sec}$ and extension at $72^{\circ} \mathrm{C}$ for $25 \mathrm{sec}$.

Western blot analysis. Cells were washed with cold PBS and lysed on ice in $400 \mu 1$ NET lysis buffer (1\% NP-40, $50 \mathrm{mM}$ Tris at $\mathrm{pH} 8.0,150 \mathrm{mM} \mathrm{NaCl}, 5 \mathrm{mM}$ EDTA, $10 \mu \mathrm{g} / \mathrm{ml}$ of aprotinin and pepstatin and $100 \mu \mathrm{g} / \mathrm{ml}$ of PMSF). Protein concentrations were determined using the Bio-Rad protein assay (Bio-Rad Laboratories). Fifty micrograms of protein were separated on $10 \%$ SDS-polyacrylamide gel electrophoresis and transferred to nitrocellulose membrane at $100 \mathrm{~V}$ for $2 \mathrm{~h}$ at $4^{\circ} \mathrm{C}$ using a Bio-Rad transfer unit. The transfer buffers consisted of $25 \mathrm{mM}$ Tris, $192 \mathrm{mM}$ glycine and $20 \%$ methanol. After transfer, the blots were blocked in $10 \%$ milk (fatty acid-free) with TBS-T (0.1\% Tween-20, $20 \mathrm{mM}$ Tris, $137 \mathrm{mM} \mathrm{NaCl}$, and $1 \mathrm{M} \mathrm{HCl}$ ). The blots were then hybridized with anti-COX-2 or anti-COX-1 goat polyclonal antibody (Santa Cruz Biotechnology, Santa Cruz, CA) in 1:1000 dilutions for $2 \mathrm{~h}$ at room temperature. As an internal control, the blots were striped and reprobed with anti- $\beta$-actin mouse monoclonal antibody (Sigma) in 1:2000 dilution for $1 \mathrm{~h}$ at room temperature. This was followed by washing in TBS-T and then incubated with horseradish peroxidase-conjugated donkey anti-goat or rabbit anti-mouse IgG (Santa Cruz Biotechnology) at 1:2000 dilution for $1 \mathrm{~h}$ at room temperature. After several washings, blots were developed using SuperSignal West Pico Western blot detection kit (Pierce, Rockford, IL).

BrdU proliferation assay. Cell proliferation was determined by Cell proliferation ELISA, BrdU (Roche, Mannheim, Germany) through the monitoring of BrdU (pyrimidine analogue) incorporation. Cells were plated on a 96-well plate 


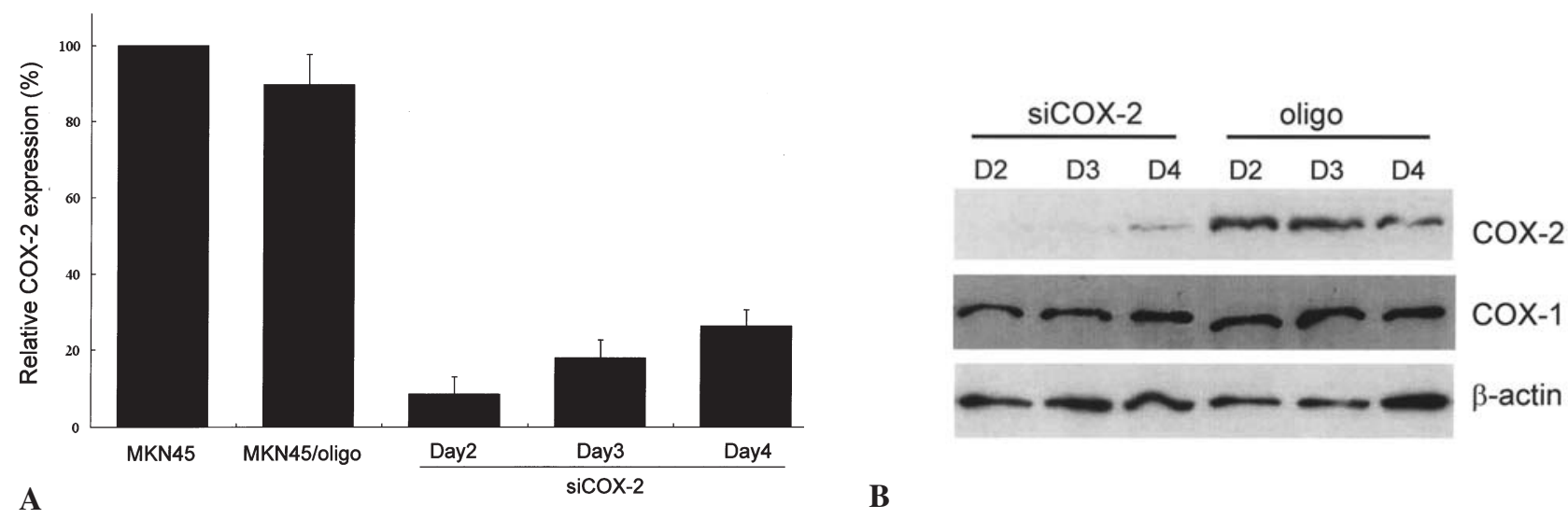

Figure 1. Specific knockdown of COX-2 by siRNA in MKN45 gastric cancer cells. Cells were transiently transfected with 400 nM siRNA against COX-2. COX-2 mRNA and protein levels were analyzed by real-time RT-PCR (A) and Western blot (B) on days 2-4 after transfection. COX-2 levels deceased to 10\% of the original on day 2 after transfection, while levels of COX-1 and B-actin (loading control) remain unchanged, suggesting that the siRNA was gene specific. In the control experiment (oligofectamine only), the levels of both COX-2 and COX-1 showed no change.

at a density of 3000 cells/well. After seeding overnight, cells were either transfected with siRNA against COX-2 or incubated with various amount of NS398.

$P G E_{2}$ production by ELISA assay. $\mathrm{PGE}_{2}$ was measured using the Biotrak $\mathrm{PGE}_{2}$ competitive enzyme immunoassay system (Amersham, Buckinghamshire, UK) according to the manufacturer's instructions. Cells were plated on a 96-well plate at a density of $1 \times 10^{4}$ cells/well. After seeding overnight, cells were either transfected with siRNA against COX-2 or incubated with various amount of NS398. Condition medium was extracted and used for $\mathrm{PGE}_{2}$ analysis. The $\mathrm{PGE}_{2}$ level was normalized to protein amount and the relative level of that day's control experiment was calculated. The results were expressed as mean \pm standard deviation of 3 independent experiments.

Cell cycle analysis. MKN45 cells were treated with either siCOX-2 or $10 \mu \mathrm{M}$ of NS398 and were cultured in the presence of $5 \mu \mathrm{g} / \mathrm{ml}$ cisplatin for $24 \mathrm{~h}$. They were then collected after brief trypsinization, washed with PBS, and fixed in $70 \%$ ethanol for $24 \mathrm{~h}$ at $4^{\circ} \mathrm{C}$. Cells were then treated with $0.1 \mathrm{mg} / \mathrm{ml}$ RNase, stained with $10 \mu \mathrm{g} / \mathrm{ml}$ propidium iodide (PI) at $37^{\circ} \mathrm{C}$ for 30 min and analyzed by FACScan flow cytometer (BectonDickinson, Franklin Lakes, NJ). The percentage of apoptotic cells in the sub-G1 area was analyzed using Cell Quest software (Becton-Dickinson). Cell-cycle distribution was quantified by ModFit LT software (Becton-Dickinson).

Colony formation assay. To assay colony formation, $5 \times 10^{5}$ cells were seeded onto $10-\mathrm{cm}$ diameter plates. Cells were transfected the following day with siCOX-2 expressing plasmid (pCOX-2) or empty vector (pSilencer-3.1-H1 neo, $\mathrm{pNEG)}$ using lipofectamine plus reagent (Invitrogen), according to the manufacturer's protocol. Twenty-four hours after transfection, cells from each plate were trypsinized and re-plated equally into $310-\mathrm{cm}$ diameter plates maintained in RPMI-1640 with $10 \%$ FBS under selection of $500 \mu \mathrm{g} / \mathrm{ml} \mathrm{G} 418$ (Invitrogen) for 14 days at $37^{\circ} \mathrm{C}$. Plates were fixed with $4 \%$ formaldehyde in PBS, and colonies were visualized by staining with $0.01 \%$ crystal violet. The number of colonies formed was counted by GeneTools ver. 3.0 (SynGene Labortories, Cambridge, UK).

In vivo tumor growth assay. Six-week-old female athymic nude mice (BALB/c nu/nu) were obtained from the Laboratory Animal Service Center of The Chinese University of Hong Kong. All mice were kept under specific pathogen-free conditions using a laminar airflow rack and had free access to sterilized food and autoclave water. All experiments were performed under a license from the government of the Hong Kong SAR and endorsed by the Animal Experimentation Ethics Committee of The Chinese University of Hong Kong.

MKN45 cells transiently transfected with either $400 \mathrm{nM}$ of COX-2 siRNA or siGL2 were injected subcutaneously $\left(1 \times 10^{6}\right.$ cells per injection) into the flank of each mouse at day 0 . Tumor size was measured daily with calipers in three dimensions: length (L), width (W), and height $(\mathrm{H})$. Tumor volume was calculated using the formula $(\pi \times \mathrm{L} \times \mathrm{W} \times \mathrm{H}) / 6$ (23). At the end of the experiment, all mice were sacrificed by cervical dislocation.

\section{Results}

Inhibition of COX-2 expression and $P G E_{2}$ production by RNAi. We first investigated the efficiency of COX-2 suppression by RNA interference. The results showed that COX-2 mRNA (Fig. 1A) and protein (Fig. 1B) was maximally inhibited by COX-2 siRNA on day 2 after transfection. There was an over $80 \%$ reduction in COX-2 mRNA expression on day 2. As shown in Fig. 1B, COX-2 protein levels gradually reexpressed on day 4 of the experiment. Protein levels of COX-1 and $B$-actin remained unchanged (Fig. 2), suggesting that our siRNA was specific.

We then investigated the effects of COX-2 siRNA on $\mathrm{PGE}_{2}$ production in MKN45 cells (Fig. 2). Maximal suppression of $\mathrm{PGE}_{2}$ production was noted on day 3 , on which it was reduced to $40 \%$ of the control (vehicles only, $\mathrm{P}<0.05$ ). In contrast, NS398 produced a potent inhibitory effect on $\mathrm{PGE}_{2}$ production on day 1 with doses as low as $1 \mu \mathrm{M}(\mathrm{P}<0.05$ vs. control). 


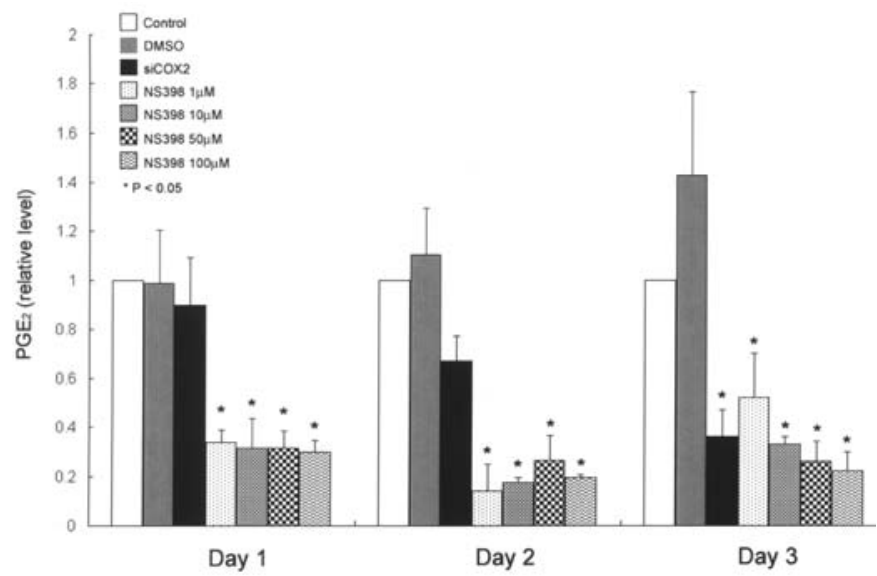

Figure 2. Relative levels of $\mathrm{PGE}_{2}$ in $\mathrm{MKN} 45$ cells after treatment with $\mathrm{COX}-2$ siRNA or NS398. Cells were either transiently transfected with $400 \mathrm{nM}$ siRNA or treated with various concentrations of the COX-2 specific inhibitor NS398. On different days, levels of $\mathrm{PGE}_{2}$ in the condition media were measured by ELISA assay. The relative level of $\mathrm{PGE}_{2}$ was determined by comparison to the level of the control experiment on the same day. On day 3, both siRNA and NS398 showed a significant reduction of $\mathrm{PGE}_{2}$ levels $(\mathrm{P}<0.05)$.

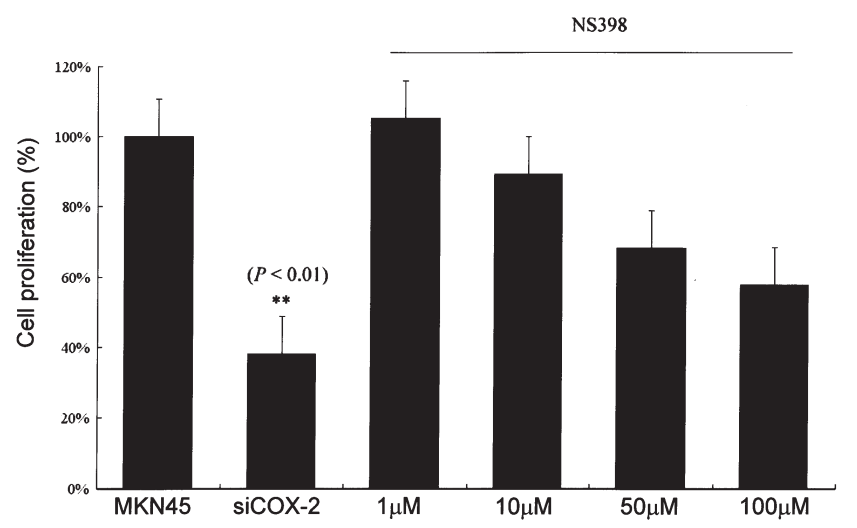

Figure 3. Effects of COX-2 siRNA on cell proliferation. Cells were transfected with either $400 \mathrm{nM}$ of COX-2 siRNA or various concentrations of NS398 on a 96-well plate. The proliferation was determined by BrdU incorporation assay. COX-2 siRNA demonstrated a significant growth inhibition of $62 \%$ on MKN45 cells $(\mathrm{P}<0.01)$. Using NS398, a similar inhibitory effect can only be observed at high $(100 \mu \mathrm{M})$ concentrations.

COX-2 siRNA inhibits cell proliferation. Previous studies have found that the COX-2 inhibitor NS398 can inhibit the growth of gastric cancer cells (24). We next determined the effects of siRNA on the proliferation of the MKN45 cells (Fig. 3). Cells were treated with either NS398 or siRNA against COX-2. Proliferation was then determined by BrdU incorporation. Specific inhibition of COX-2 by siRNA reduced cell growth by $62 \%$ as compared to the control (vehicles only; $\mathrm{P}<0.01$ ). NS398 showed a dose-dependent inhibition of cell proliferation. However, only $10 \%$ growth reduction was observed in MKN45 cells treated with $10 \mu \mathrm{M}$ of NS398 and the inhibitory effect of $100 \mu \mathrm{M} \mathrm{NS398} \mathrm{was}$ still less than that of siRNA (Fig. 3).
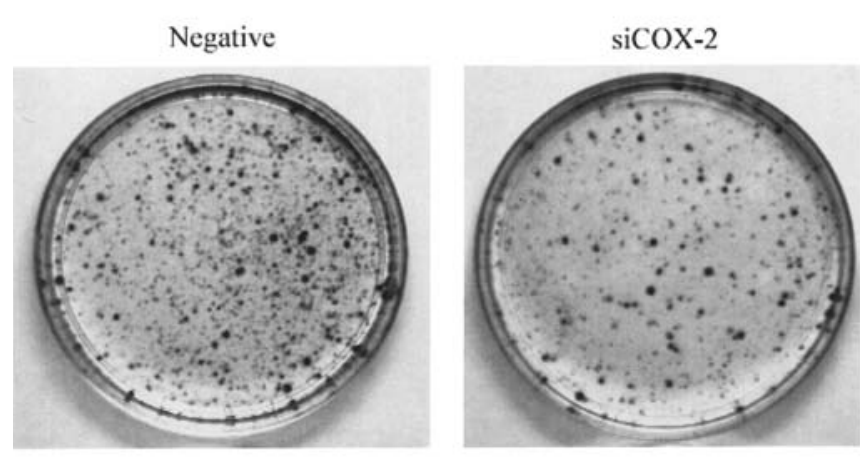

Figure 4. Effects of COX-2 siRNA on the colony formation on MKN45 cells. Cells were transiently transfected with either plasmid expressing COX-2 siRNA (siCOX-2) or scramble siRNA (negative control). Colonies were formed after 14 days of G418 selection. Cells transfected with COX-2 siRNA showed a significant reduction in colonies formation $(\mathrm{P}<0.05)$.

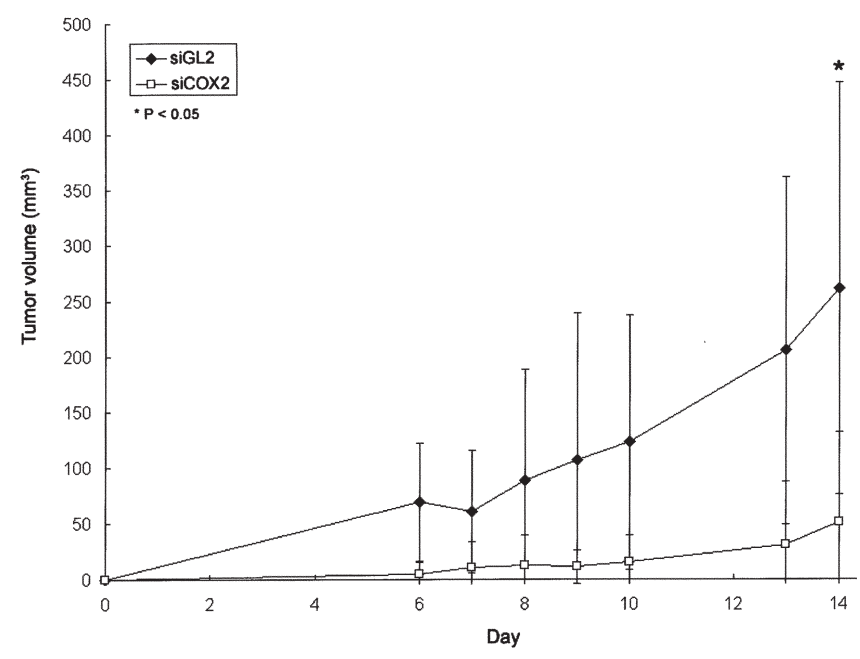

Figure 5. Effects of COX-2 siRNA on tumor growth in vivo. MKN45 cells transiently transfected either with COX-2 siRNA (open box) or luciferase siRNA (black box) were injected subcutaneously into athymic nude mice. Tumor volumes were measured after day 6 . At day 14, the tumor with COX-2 siRNA had a significantly smaller volume $(\mathrm{P}<0.05)$. Data were expressed as mean $\pm \operatorname{SD}(\mathrm{n}=4)$.

COX-2 siRNA reduced cell growth in colony formation assay. To further determine the effect of COX-2 siRNA on the growth of MKN45 cells, we transiently transfected the cells with plasmid expressing COX-2 siRNA (pCOX-2). As a control experiment, plasmid expressing siRNA with no homology to human genome (scramble) was transfected into the cells. After 14 days of G418 selection, the colonies obtained were stained and counted (Fig. 4). Cells transfected with pCOX-2 showed a significant reduction in the number of colonies $(82 \pm 7$ colonies vs. $122 \pm 11$ colonies, $\mathrm{P}<0.05)$.

COX-2 siRNA reduced tumor growth in vivo. To examine the effects of siCOX2 on MKN45 cells in vivo, cells transfected with either siCOX2 or siGL2 were injected subcutaneously into nude mice. Tumor growth from cells injected with siCOX2 was first observed on day 6 after the injection of the MKN45 cells (Fig. 5). After 14 days, there was a significant difference 


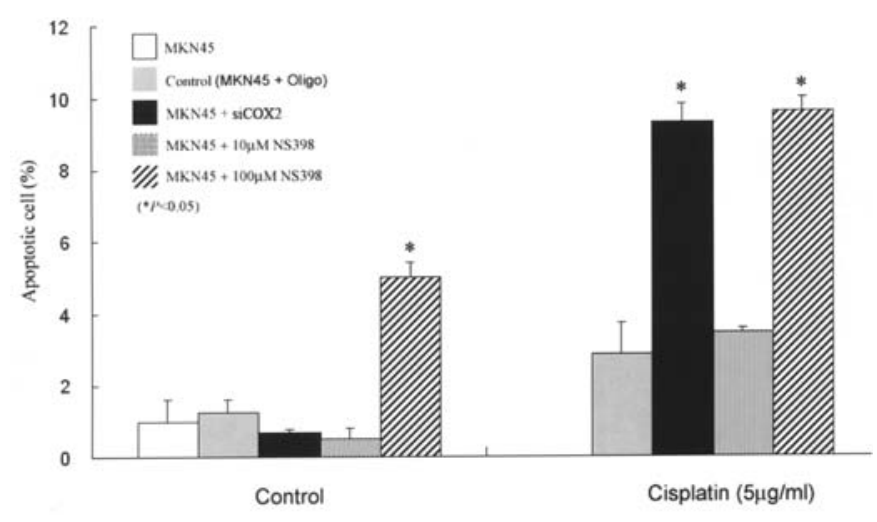

Figure 6 . Analysis of apoptotic cells by flow cytometry. MKN45 cells treated with COX-2 siRNA or NS398 were subjected to a cisplatin-induced chemosensitivity assay as determined by the flow cytometry. COX-2 siRNA and $100 \mu \mathrm{M}$ of NS398 significantly increased the apoptosis of MKN45 cells in combination with cisplatin treatment. Data were expressed as mean $\pm \mathrm{SD}$ $(\mathrm{n}=3)\left({ }^{*} \mathrm{P}<0.05\right.$ as compared to control, oligofectamine only).

in tumor volume between cells transfected with siCOX2 and siGL2 (51.2 $\pm 79.8 \mathrm{~mm}^{3}$ vs. $\left.261.3 \pm 185.8 \mathrm{~mm}^{3}, \mathrm{P}<0.05\right)$.

Effect of COX-2 siRNA on cisplatin-induced apoptosis in MKN45 cells. The effects of COX-2 siRNA on apoptosis was determined by flow cytometry (Fig. 6). Treatment with $100 \mu \mathrm{M}$ of NS398 significantly increased apoptosis $(\mathrm{P}<0.05)$. On the other hand, transfection with COX-2 siRNA or treatment with $10 \mu \mathrm{M}$ of NS398 showed no significant induction of apoptosis as compared to the control MKN45 cells. Notably, COX-2 siRNA significantly potentiated the effects of cisplatin-induced $(5 \mu \mathrm{g} / \mathrm{ml})$ apoptosis on gastric cancer cells $(\mathrm{P}<0.05$, Fig. 6) The pro-apoptotic effect was comparable to treatment with $100 \mu \mathrm{M}$ of NS398, suggesting that COX-2 siRNA enhances the chemosensitivity of MKN45 cells to cisplatin.

\section{Discussion}

Overexpression of COX-2 is associated with gastric carcinogenesis. Several earlier studies, including ours, have investigated the role of COX-2 in human gastric carcinomas $(9,10,12,25,26)$. These studies provide the basis for the use of COX-2 inhibitors on chemoprevention and the treatment of gastric cancer. However, the existence of possible COX-2 independent effects may raise concerns about the role of COX-2 inhibition $(27,28)$. In light of these findings, we investigated the role of specific inhibition of COX-2 expression by RNAi and its effect on tumor growth.

Our data show that COX-2 siRNA can specifically suppress COX-2 mRNA and protein expression levels in the MKN45 gastric cancer cell line. Moreover, $\mathrm{PGE}_{2}$ production was effectively suppressed by siRNA to a level comparable to treatment with NS398. COX-2 siRNA resulted in significant growth inhibition of MKN45 both in vitro and in vivo. Unlike treatment with high doses of NS398, the anti-proliferative effect of COX-2 siRNA was not associated with a significant induction of apoptosis. Although several reports have demonstrated that NS398 induces growth inhibition in a dosedependent manner (29-31), the inhibitory effect of NS398 at high concentrations is associated with the induction of apoptosis via COX-2 independent pathways $(13,32)$. Our results are also in keeping with a previous report by Denkert et al, which demonstrates that the growth inhibitory effect of COX-2 siRNA is not associated with the induction of apoptosis (33). Together, the results imply that the specific function of COX-2 in gastric cancer therapy is not linked to apoptotic machinery.

Defects in apoptosis are important in tumorigenesis as well as in the treatment of cancer. A number of chemotherapeutic agents have been shown to induce apoptosis. However, most gastric cancers are not responsive to chemotherapy, suggesting that these tumors are intrinsically resistant to apoptosis-inducing agents $(34,35)$. We therefore examined siRNA to see if it could enhance the sensitivity of MKN45 towards chemotherapeutic agents. While COX-2 siRNA alone had no significant effect on apoptosis induction, cells transfected with siRNA experienced a significant increase in cisplatin-induced apoptosis. A similar synergistic effect, however, can only be observed at high concentrations of NS398, which is likely medicated through COX-2 independent pathway. Previous reports have shown that $100 \mu \mathrm{M}$ of NS398 can enhance various chemotherapeutic druginduced apoptosis in hypopharyngeal carcinoma (31).

Recently, several reports were published demonstrating that RNAi-mediated COX-2 inhibition can prevent growth in prostate and colon cancer cells $(36,37)$. Our results demonstrate for the first time that, in gastric cancer, siRNA used against COX-2 can inhibit tumor growth and enhance cisplatininduced apoptosis. The potential of using COX-2 as a therapeutic target for the treatment and prevention of cancer has been very encouraging. However, recent reports on cardiovascular complications related to long-term use of COX-2 inhibitors have raised safety concerns $(38,39)$. Silencing COX-2 by RNA interference as demonstrated in this study may prove to be a more promising approach to gastric cancer therapy.

\section{Acknowledgements}

This study was supported by a direct grant from The Chinese University of Hong Kong.

\section{References}

1. Du Bois RN, Abramson SB, Crofford L, Gupta RA, Simon LS, van de Putte LB and Lipsky PE: Cyclooxygenase in biology and disease. FASEB J 12: 1063-1073, 1998.

2. Leung WK, To KF, Ng YP, Lee TL, Lau JY, Chan FK, Ng EK, Chung SC and Sung JJ: Association between cyclo-oxygenase-2 overexpression and missense p53 mutations in gastric cancer. $\mathrm{Br}$ J Cancer 84: 335-339, 2001.

3. Ristimaki A, Sivula A, Lundin J, Lundin M, Salminen T, Haglund C, Joensuu $\mathrm{H}$ and Isola J: Prognostic significance of elevated cyclooxygenase- 2 expression in breast cancer. Cancer Res 62: 632-635, 2002.

4. Williams CS, Tsujii M, Reese J, Dey SK and Du Bois RN: Host cyclooxygenase-2 modulates carcinoma growth. J Clin Invest 105: 1589-1594, 2000.

5. Liu CH, Chang SH, Narko K, Trifan OC, Wu MT, Smith E, Haudenschild C, Lane TF and Hla T: Overexpression of cyclooxygenase- 2 is sufficient to induce tumorigenesis in transgenic mice. J Biol Chem 276: 18563-18569, 2001.

6. Tsujii M and Du Bois RN: Alterations in cellular adhesion and apoptosis in epithelial cells overexpressing prostaglandin endoperoxide synthase 2. Cell 83: 493-501, 1995. 
7. Pisani P, Parkin DM, Bray F and Ferlay J: Estimates of the worldwide mortality from 25 cancers in 1990. Int J Cancer 83: 18-29, 1999.

8. Lee TL, Leung WK, Lau JY, Tong JH, Ng EK, Chan FK, Chung SC, Sung JJ and To KF: Inverse association between cyclooxygenase- 2 overexpression and microsatellite instability in gastric cancer. Cancer Lett 168: 133-140, 2001.

9. Chen CN, Sung CT, Lin MT, Lee PH and Chang KJ: Clinicopathologic association of cyclooxygenase 1 and cyclooxygenase 2 expression in gastric adenocarcinoma. Ann Surg 233: 183-188, 2001.

10. Hu PJ, Yu J, Zeng ZR, Leung WK, Lin HL, Tang BD, Bai AH and Sung JJ: Chemoprevention of gastric cancer by celecoxib in rats. Gut 53: 195-200, 2004

11. Farrow DC, Vaughan TL, Hansten PD, Stanford JL, Risch HA, Gammon MD, Chow WH, Du Brow R, Ahsan H, Mayne ST, Schoenberg JB, West AB, Rotterdam H, Fraumeni JF Jr and Blot WJ: Use of aspirin and other nonsteroidal anti-inflammatory drugs and risk of esophageal and gastric cancer. Cancer Epidemiol Biomarkers Prev 7: 97-102, 1998.

12. Sawaoka H, Kawano S, Tsuji S, Tsujii M, Gunawan ES, Takei Y, Nagano K and Hori M: Cyclooxygenase-2 inhibitors suppress the growth of gastric cancer xenografts via induction of apoptosis in nude mice. Am J Physiol 274: G1061-G1067, 1998.

13. Minter HA, Eveson JW, Huntley S, Elder DJ and Hague A: The cyclooxygenase 2-selective inhibitor NS398 inhibits proliferation of oral carcinoma cell lines by mechanisms dependent and independent of reduced prostaglandin E2 synthesis. Clin Cancer Res 9: 1885-1897, 2003.

14. Yip-Schneider MT, Barnard DS, Billings SD, Cheng L, Heilman DK, Lin A, Marshall SJ, Crowell PL, Marshall MS and Sweeney CJ: Cyclooxygenase-2 expression in human pancreatic adenocarcinomas. Carcinogenesis 21: 139-146, 2000.

15. Jendrossek V, Handrick R and Belka C: Celecoxib activates a novel mitochondrial apoptosis signaling pathway. FASEB J 17: $1547-1549,2003$

16. Dykxhoorn DM, Novina CD and Sharp PA: Killing the messenger: short RNAs that silence gene expression. Nat Rev Mol Cell Biol 4: 457-467, 2003.

17. Wilson JA, Jayasena S, Khvorova A, Sabatinos S, RodrigueGervais IG, Arya S, Sarangi F, Harris-Brandts M, Beaulieu S and Richardson CD: RNA interference blocks gene expression and RNA synthesis from hepatitis $C$ replicons propagated in human liver cells. Proc Natl Acad Sci USA 100: 2783-2788, 2003.

18. Caplen NJ, Parrish S, Imani F, Fire A and Morgan RA: Specific inhibition of gene expression by small double-stranded RNAs in invertebrate and vertebrate systems. Proc Natl Acad Sci USA 98: 9742-9747, 2001

19. Leung WK, Bai AH, Chan VY, Yu J, Chan MW, To KF, Wu JR, Chan KK, Fu YG, Chan FK and Sung JJ: Effect of peroxisome proliferator activated receptor gamma ligands on growth and gene expression profiles of gastric cancer cells. Gut 53: 331-338, 2004.

20. Barnett J, Chow J, Ives D, et al: Purification, characterization and selective inhibition of human prostaglandin $\mathrm{G} / \mathrm{H}$ synthase 1 and 2 expressed in the baculovirus system. Biochim Biophys Acta 1209: 130-139, 1994

21. Elbashir SM, Harborth J, Lendeckel W, Yalcin A, Weber K and Tuschl T: Duplexes of 21-nucleotide RNAs mediate RNA interference in cultured mammalian cells. Nature 411: 494-498, 2001.

22. Cheng AS, Chan HL, Leung WK, Wong N, Johnson PJ and Sung JJ: Specific COX-2 inhibitor, NS-398, suppresses cellular proliferation and induces apoptosis in human hepatocellular carcinoma cells. Int J Oncol 23: 113-119, 2003.
23. Itami A, Watanabe G, Shimada Y, Hashimoto Y, Kawamura J, Kato M, Hosotani R and Imamura M: Ligands for peroxisome proliferator-activated receptor gamma inhibit growth of pancreatic cancers both in vitro and in vivo. Int J Cancer 94: 370-376, 2001.

24. Sawaoka H, Kawano S, Tsuji S, Tsujii M, Murata H and Hori M Effects of NSAIDs on proliferation of gastric cancer cells in vitro: possible implication of cyclooxygenase- 2 in cancer development. J Clin Gastroenterol 27 (Suppl. 1): S47-S52, 1998.

25. Ristimaki A, Honkanen N, Jankala H, Sipponen $\mathrm{P}$ and Harkonen M: Expression of cyclooxygenase-2 in human gastric carcinoma. Cancer Res 57: 1276-1280, 1997.

26. Sung JJ, Leung WK, Go MY, To KF, Cheng AS, Ng EK and Chan FK: Cyclooxygenase-2 expression in Helicobacter pyloriassociated premalignant and malignant gastric lesions. Am J Pathol 157: 729-735, 2000.

27. Wong BC, Jiang XH, Lin MC, Tu SP, Cui JT, Jiang SH, Wong WM, Yuen MF, Lam SK and Kung HF: Cyclooxygenase-2 inhibitor (SC-236) suppresses activator protein-1 through c-Jun NH2-terminal kinase. Gastroenterology 126: 136-147, 2004.

28. Jiang XH, Lam SK, Lin MC, Jiang SH, Kung HF, Slosberg ED, Soh JW, Weinstein IB and Wong BC: Novel target for induction of apoptosis by cyclo-oxygenase-2 inhibitor SC-236 through a protein kinase C-beta(1)-dependent pathway. Oncogene 21: 6113-6122, 2002

29. Park MK, Hwang SY, Kim JO, Kwack MH, Kim JC, Kim MK and Sung YK: NS398 inhibits the growth of Hep3B human hepatocellular carcinoma cells via caspase-independent apoptosis. Mol Cells 17: 45-50, 2004

30. Yao M, Lam EC, Kelly CR, Zhou W and Wolfe MM: Cyclooxygenase-2 selective inhibition with NS-398 suppresses proliferation and invasiveness and delays liver metastasis in colorectal cancer. Br J Cancer 90: 712-719, 2004.

31. Peng JP, Liu LT, Chang HC and Hung WC: Enhancement of chemotherapeutic drug-induced apoptosis by a cyclooxygenase-2 inhibitor in hypopharyngeal carcinoma cells. Cancer Lett 201: 157-163, 2003.

32. Zhong H, Willard M and Simons J: NS398 reduces hypoxiainducible factor (HIF)-1alpha and HIF-1 activity: multiple-level effects involving cyclooxygenase- 2 dependent and independent mechanisms. Int J Cancer 112: 585-595, 2004.

33. Denkert C, Furstenberg A, Daniel PT, Koch I, Kobel M, Weichert W, Siegert A and Hauptmann S: Induction of G0/G1 cell cycle arrest in ovarian carcinoma cells by the anti-inflammatory drug NS-398, but not by COX-2-specific RNA interference. Oncogene 22: 8653-8661, 2003.

34. Moertel CG: Clinical management of advanced gastrointestinal cancer. Cancer 36: 675-682, 1975.

35. Gottesman MM: Mechanisms of cancer drug resistance. Annu Rev Med 53: 615-627, 2002.

36. Narayanan BA, Narayanan NK, Davis L and Nargi D: RNA interference-mediated cyclooxygenase- 2 inhibition prevents prostate cancer cell growth and induces differentiation: modulation of neuronal protein synaptophysin, cyclin D1, and androgen receptor. Mol Cancer Ther 5: 1117-1125, 2006.

37. Strillacci A, Griffoni C, Spisni E, Manara MC and Tomasi V: RNA interference as a key to knockdown overexpressed cyclooxygenase-2 gene in tumour cells. Br J Cancer 94: 1300-1310, 2006

38. Bresalier RS, Sandler RS, Quan H, Bolognese JA, Oxenius B, Horgan K, Lines C, Riddell R, Morton D, Lanas A, Konstam MA and Baron JA: Cardiovascular events associated with rofecoxib in a colorectal adenoma chemoprevention trial. N Engl J Med 352: 1092-1102, 2005.

39. Drazen JM: COX-2 inhibitors - a lesson in unexpected problems. N Engl J Med 352: 1131-1132, 2005. 